\title{
A FORMAÇÃO DOCENTE E O PIBID-SUBPROJETO DE BIOLOGIA DO IFRN/MACAU: UMA INTERLOCUÇÃO ENTRE A FORMAÇÃO INICIAL E CONTINUADA
}

\author{
G. R. de LIMA ${ }^{1}$, M. A. dos S. FERREIRA ${ }^{2}$ \\ ${ }^{1,2}$ Instituto Federal de Educação, Ciência e Tecnologia do Rio Grande de Norte \\ gislaine_ppg@ hotmail $^{1}$
}

Submetido 22/02/2017 - Aceito 05/03/2018

DOI: $10.15628 /$ holos.2018.4701

\section{RESUMO}

Este estudo tem como objetivo analisar o Programa Institucional de Bolsa de Iniciação à Docência (PIBID), subprojeto de biologia desenvolvido no curso de licenciatura plena em Biologia do IFRN-Campus Macau/RN, e as suas contribuições com a interlocução entre a formação inicial dos licenciandos e a formação continuada dos professores supervisores do programa. A pesquisa consistiu-se em uma abordagem qualitativa, cujo instrumento de coleta de dados configurou-se em uma entrevista semiestruturada. Nas entrevistas, os participantes do subprojeto biologia (licenciandos e professores supervisores) foram indagados a partir de suas experiências no PIBID, cujos questionamentos foram organizados em duas categorias de análise: formação inicial e formação continuada. Ao analisar as perspectivas dos licenciandos sobre a interlocução entre
\end{abstract}

formação inicial e continuada a partir do PIBID percebeu-se que estes visualizam o espaço escolar como um ambiente colaborativo, em que os professores supervisores contribuem para a formação dos licenciandos, ao mesmo tempo em que ao orientar os iniciantes a docência estes professores adquirem novas experiências que serão significativas para seu processo formativo contínuo. Diante das conquistas percebidas e das perspectivas vislumbradas, acredita-se que a atuação do PIBID tem sido positiva na comunidade escolar, contribuindo para o processo formativo de todos os envolvidos, desde os bolsistas de iniciação à docência, até os professores supervisores, mesmo estes não percebendo que ao mesmo tempo em que "eles formam, também se formam".

PALAVRAS-CHAVE: PIBID, Formação inicial docente, Formação continuada docente.

\section{THE TEACHER TRAINING AND PIBID / SUBPROJECT BIOLOGY OF IFRN / MACAU: A INTERLOCUTION BETWEEN INITIAL TRAINING AND CONTINUING}

\begin{abstract}
This study object to analyze the Institutional Program Initiation to Teaching Scholarship (PIBID), Biology subproject developed in the course of full degree in IFRN Biology-Campus Macau/RN, and contributions to the interlocution between the initial training of graduates and continuing the supervising teachers of the program. The research is in a qualitative approach, whose data collection instrument set up in a semistructured interview. In interviews, participants subproject biology (undergraduate and supervising teachers) were asked from his experiences in PIBID, whose questions were organized into two categories of analysis: initial training and continuing education. In analyzing the prospects for future teachers about the
\end{abstract}

dialogue between initial and continuing education from PIBID was realized that they view the school as collaborative environment where supervisors teachers contribute to the initial training of undergraduates at the same point where the beginners guide to teaching these teachers acquire new experiences that are also significant for its training process, providing continuing education. On the achievements already realized and envisioned perspectives, it is believed that the performance of PIBID has been positive in the school community, contributing to the training process of all those involved, from the initiation scholarship to teaching, to the supervising teachers, even these not realizing at the same time that "they form, also form".

KEYWORDS: PIBID, Initial teacher training, Continuing teacher training. 


\section{INTRODUÇÃO}

A necessidade de repensar a formação docente no Brasil em uma perspectiva renovadora tornou-se pauta recorrente nas discussões atuais no âmbito da educação, principalmente pela necessidade de formar um profissional qualificado que adentre na educação básica motivado e preparado para lidar com a realidade escolar.

Nesse sentido, o Programa Institucional de Bolsas de Iniciação à Docência (PIBID) respaldado pelas leis Lei $\mathrm{n}$ - 9.394/1996, Lei ํo 12.796/2013 e aprovado pelo Decreto $\mathrm{n}$ ㅇ $7.219 / 2010$, surge como estratégia política para além de outros objetivos, a valorização do magistério, qualificação do profissional docente e inserção dos licenciandos na realidade escolar desde o processo de formação inicial.

Tendo em vista estes objetivos propostos pelo programa e o interesse em conhecer as potencialidades do mesmo quanto à formação docente, procurou-se desenvolver esta pesquisa a partir da seguinte problemática: A política do PIBID contribui com a interlocução entre formação inicial dos bolsistas de iniciação à docência e continuada dos professores supervisores que participam programa?

Dessa forma, a produção desse construto tem como objetivo principal analisar o PIBID e as suas contribuições com a interlocução entre formação inicial dos licenciados - bolsistas de iniciação à docência e continuada dos professores supervisores do subprojeto biologia desenvolvido no Curso de Licenciatura Plena em Biologia ofertado pelo Instituto Federal de Educação, Ciência e Tecnologia do Rio Grande do Norte - Campus Macau.

\section{METODOLOGIA}

Considerando o propósito de analisar a perspectiva dos agentes que fazem parte do programa, sejam estes licenciandos e professores supervisores, no que diz respeito a interlocução da formação inicial e continuada a partir do PIBID, o caminho metodológico orientou-se naturalmente para uma aproximação à perspectiva dos sujeitos.

Sendo assim, chegou-se a conclusão que o perfil desta pesquisa segue um caráter qualitativo, e para alcançar o intento do estudo foi utilizada a entrevista semiestruturada, já que esta tornou-se um instrumento de coleta de dados eficiente frente a necessidade de captar as percepções dos participantes, diante da problemática estudada. Como fundamentação teórica da pesquisa foram utilizados estudos de autores que discutem sobre a formação docente, entre eles: Freire (1996), Pimenta (2008), Farias (2009) e Cunha (2014).

Dos bolsistas licenciandos participantes do subprojeto biologia, que no período correspondente à pesquisa consistiam de 28 bolsistas, foram entrevistados um total de 13 bolsistas, sendo que destes 08 atuavam na Escola Estadual Professora Clara Téteo, localizada no município de Macau/RN e 05 na Escola Estadual Monsenhor Honório, situada no município de Pendências/RN. Em relação aos professores supervisores, foram entrevistados 02 professores dentre os 03 que faziam parte do programa, sendo que os 02 docentes entrevistados atuavam na Escola Estadual Professora Clara Téteo. Infelizmente por motivos pessoais a professora supervisora atuante na Escola de Pendências/RN não participou da referida pesquisa. 
A fim de resguardar as identidades dos participantes da pesquisa fez-se uso de pseudônimos, substituindo os nomes dos entrevistados por nomes de espécies de plantas e aves encontradas na caatinga, bioma característico da região nordeste do país.

Dos licenciandos entrevistados, 02 estavam cursando o 5o período do curso de Licenciatura em Biologia, 04 estavam no 70 período e 07 eram concluintes do referido curso, como pode-se observar na Tabela 1 representada logo abaixo.

Tabela 1: Número de licenciandos participantes da pesquisa e os respectivos períodos que se encontravam matriculados no curso.

\begin{tabular}{lc}
\hline PERÍODOS & ENTREVISTADOS \\
\hline 5o Período & 02 \\
\hline 70 Período & 04 \\
\hline Concluinte & 07 \\
\hline TOTAL & 13 \\
\hline
\end{tabular}

Para realização das entrevistas foi levado em conta duas categorias a serem exploradas a partir de questionamentos realizados aos entrevistados, como pode-se observar no Quadro 1:

Quadro 1: Categorias e questões correspondentes analisadas na pesquisa.

\begin{tabular}{|c|l|}
\hline CATEGORIAS DE ANÁLISE & \multicolumn{1}{c|}{ QUESTÕES CORRESPONDENTES } \\
\hline FORMAÇÃO INICIAL & • Relevância do programa na formação inicial dos licenciandos. \\
\hline FORMAÇÃO CONTINUADA & $\begin{array}{l}\text { - Relevância do programa na formação continuada dos professores } \\
\text { supervisores. } \\
\text { - Perspectiva sobre a interlocução entre formação inicial e } \\
\text { continuada a partir do PIBID. }\end{array}$ \\
\hline
\end{tabular}

As questões correspondentes a cada uma das categorias foram expostas para os participantes da pesquisa a partir da organização de um roteiro de entrevistas. O que foi realizado no trabalho foi categorizar os questionamentos a partir de dois temas principais: formação inicial, e formação continuada, a fim de facilitar a análise das falas dos entrevistados e criar um paralelo entre as perspectivas dos licenciandos e dos professores supervisores.

\section{O PIBID: UMA ESTRATÉGIA POLÍTICA DE FORMAÇÃO INICIAL E CONTINUADA}

O PIBID surgiu como uma estratégia decorrente dos movimentos das políticas públicas na área da educação, visando suprir a defasagem de professores formados, qualificados e atuantes na educação básica, bem como mudar o quadro de desvalorização da prática docente no país. 
Esse programa é desenvolvido pela Coordenação de Aperfeiçoamento de Pessoal de Nível Superior (CAPES) em parceria com as Instituições de Ensino Superior, tendo por finalidade fomentar a iniciação à docência, a partir do oferecimento de bolsas aos licenciandos participantes do programa, contribuindo para o aperfeiçoamento da formação de docentes em nível superior e para a melhoria da qualidade da educação básica pública brasileira (Brasil, 2013).

O licenciando devidamente matriculado em um curso de licenciatura e que integra o projeto institucional da instituição de educação superior, atua em parceria com docentes de escolas públicas, que participam como supervisores no desenvolvimento de dinâmicas, aulas práticas, produção de modelos didáticos e jogos, além da produção de artigos científicos.

Nesse sentido, o PIBID contribui para formação acadêmica dos licenciandos na medida em que estes desenvolvem tais atividades a partir do conhecimento advindo das disciplinas ministradas durante o curso, e também para a formação profissional, pois o programa incentiva a construção de um professor pesquisador, que não somente procura uma melhoria no processo de aprendizagem, mas também busca questionar e refletir criticamente sobre sua realidade, divulgando suas descobertas para a comunidade através de artigos científicos, como pode-se perceber na fala de Cunha (2014, p. 28):

\footnotetext{
O projeto também tem possibilitado a formação profissional através das produções científicas desenvolvidas no decorrer da trajetória acadêmica, tais como, publicações de artigos, resumos, participações em eventos e ainda às produções de cunho cultural como, por exemplo: apresentações teatrais e musicais, entre outras atividades.
}

Ao mesmo tempo, o PIBID também conta com a participação de professores da Instituição de Ensino Superior que atuam como coordenadores de área, e de gestão de processos educacionais, além de um coordenador institucional. Todos esses sujeitos recebem bolsas e atuam no PIBID com suas respectivas funções auxiliando no andamento do projeto.

Entre os objetivos propostos pelo programa estão o incentivo e valorização da formação docente em nível superior para educação básica, a relação entre educação superior e educação básica, e a elevação da qualidade da formação inicial dos licenciandos (Brasil, 2013).

Tais aspectos são relevantes, pois muitos alunos dos cursos de licenciatura preferem não seguir a docência, optando por atuarem em outras áreas, nesse sentido, o PIBID propõe uma forma de envolver novamente os acadêmicos dos cursos de licenciaturas em atividades que valorizem e incentivem a carreira docente, além de lhes proporcionar um âmbito de construção de conhecimento que contribua para solucionar problemas e conflitos interiores referentes à prática docente e o processo de ensino-aprendizagem, e assim, procurar elevar a qualidade de ensino da escola pública.

Além do que, o programa permite que o licenciando conheça a realidade da escola e as possibilidades concretas de exercer a docência, podendo relacionar o conhecimento que aprendeu teoricamente na prática, e tendo contato com alunos de educação básica e professores supervisores, aspectos que tornam a formação inicial muito mais significativa.

No contato com a prática, os bolsistas do programa vivenciam situações que só seriam possíveis durante o estágio, ou somente quando estes atuassem em sala, e conseguem visualizar 
de forma concreta os conhecimentos que foram trabalhados na teoria, principalmente, os pedagógicos, que por vezes são considerados cansativos e desestimulantes pelos próprios licenciandos.

De acordo com Oliveira (2012) um caráter inédito do PIBID é a viabilização de encontros sistemáticos entre professores universitários, licenciandos em formação inicial e professores supervisores de escolas públicas da educação básica, com o objetivo de discutir e promover práticas pedagógicas inovadoras e processos de aprendizagem significativos, que faz do PIBID um programa que envolve esses agentes ativamente na realidade educacional da comunidade onde estes estão inseridos, auxiliando no desenvolvimento humano e social a partir de uma educação de qualidade.

Muitos trabalhos evidenciam a relevância do PIBID como prática formativa na formação inicial. Em sua pesquisa Weber et al. (2012) apresentam um relato das experiências vivenciadas pelos bolsistas do PIBID do Departamento de Química da Universidade Federal da Paraíba (UFPB), sendo estas analisadas em consonância com a relevância do programa para os alunos da educação básica e a formação docente, em que chegaram à conclusão de que a participação dos alunos da licenciatura no projeto tem se mostrado uma oportunidade enriquecedora para a construção de uma identidade docente reflexiva e inovadora.

Fortalecendo esta perspectiva Paredes e Guimarães (2012) tecem apontamentos acerca do programa e sua contribuição para melhoria da formação inicial de professores de biologia, física e química em uma universidade do estado do Paraná, os autores enaltecem a escola da educação básica como espaço de investigação e aplicação de estratégias inovadoras, levando em consideração a realidade em que estão inseridos, tornando o espaço escolar um campo de experiência para a produção de novos conhecimentos durante a formação docente.

Oliveira (2012) discute o programa na realidade da Universidade Federal de Minas (UFMG), apresentando seus objetivos, suas ações e seus desafios, a partir de apontamentos sobre os aspectos que fazem do PIBID um programa inédito no cenário educacional brasileiro, entre as quais está o diálogo efetivo entre instituições de nível superior e escolas da educação básica, possibilitando um atendimento das especificidades que marcam diferentes demandas educacionais de um país de dimensões continentais como o Brasil.

A autora exalta a importância do programa para formação inicial já que busca a efetivação de metodologias de ensino diferenciadas, e relação entre teoria e prática tanto discutida nas questões que envolvem a formação docente. Ainda é relatada a relevância do programa para a formação continuada, a qual permite aprofundar a formação de professores por meio da docência, na participação em projetos temáticos, monitorias, oficinas nas escolas de educação básica.

Nesse contexto o PIBID entra como política para formação de docentes conscientes e reflexivos sobre sua prática.

Na realidade do IFRN- Campus Macau o PIBID atua a partir do subprojeto biologia, no qual os agentes envolvidos têm a oportunidade de colocar em prática saberes adquiridos no decorrer do curso, e a partir do contato com a realidade da escola podem refletir sobre a prática de ensino de biologia, a forma de trabalhar os conteúdos, a aplicação de metodologias diferenciadas, e a interdisciplinaridade. 


\section{O PIBID: UMA INTERLOCUÇÃO ENTRE A FORMAÇÃO INICIAL E CONTINUADA- PERCEPÇÃO DOS BOLSISTAS LICENCIANDOS E PROFESSORES SUPERVISORES}

Conforme o questionamento envolvendo a categoria de análise de formação inicial, os licenciandos enfatizam a relevância do PIBID, principalmente, no que se refere à experiência que este proporciona em sala de aula, ou seja, o contato com a prática docente, a partir do planejamento e realização de atividades diferenciadas, do contato com os alunos e das dificuldades enfrentadas. É possível perceber esta realidade nos seguintes trechos:

Nos possibilita o contato com a realidade escolar, ele me proporcionou uma experiência, como por exemplo, um melhor domínio em sala, pois com o programa a gente tem contato com o público o qual iremos trabalhar... (BARAÚNA, ENTREVISTA, 2015).

Você passa a compreender a dinâmica da escola, começa a interagir melhor com os alunos, e não sai do curso sem nenhuma experiência de como se portar na sala, de como preparar uma aula, para ter uma vivência antes de chegar no nosso trabalho (PALMA, ENTREVISTA, 2015).

O programa possui papel importante por que aprendemos no dia a dia com a prática, e a gente já vai observando as dificuldades que podemos ter futuramente (QUIPÁ, ENTREVISTA, 2015).

Eu acho o PIBID muito importante, por que é a oportunidade que eu tenho de botar em prática o que estou vendo aqui na faculdade, de lidar com alunos, mesmo antes da conclusão da licenciatura, sendo extremamente importante para minha formação (CARNAÚBA, ENTREVISTA, 2015).

As falas dos licenciandos revelam a necessidade do conhecimento prático docente no processo formativo, que, de acordo com Carter (1999) apud Marcelo (1998, p. 52) "se refere, de forma ampla, ao conhecimento que os professores possuem sobre as situações de classe e os dilemas práticos que se apresentam para levar a cabo metas educativas nessas situações", como eles próprios relataram, a prática é o momento de conhecer a realidade dos alunos, os problemas, as dificuldades e os anseios dos licenciandos que se materializam a partir desta aproximação com a realidade escolar.

De acordo com Farias et al. (2009, p.69), "o professor desenvolve sua atividade profissional e se constitui como tal, também e principalmente, no espaço escolar", sendo assim, desde a formação inicial os futuros docentes devem ter contato com a realidade escolar, algo que o PIBID possibilita desde os primeiros momentos do licenciando no curso de formação.

Os relatos dos licenciandos mostram que na percepção deles, o PIBID oportuniza experiências que serão de grande importância quando estes adentrarem no mercado de trabalho, tornando-os mais preparados para assumir a docência.

Neste ponto é válido relatar que muitos pesquisadores em seus trabalhos vêm chamando a atenção para a complexidade de um conjunto de saberes necessários para a docência, sendo a experiência um destes saberes.

Na perspectiva de Pimenta (2008), os saberes docentes são categorizados da seguinte maneira: saberes do conhecimento, que são aqueles conhecimentos produzidos socialmente, 
configurados nas áreas específicas das diferentes licenciaturas; os saberes pedagógicos, que são os conhecimentos necessários a condução da atividade docente, viabilizando o processo de ensino em diferentes espaços educativos; e os saberes da experiência, que trata-se do conjunto de conhecimentos e situações que o professor vivenciou fora e dentro dos muros da escola.

Nessa óptica, os saberes do conhecimento são aqueles desenvolvidos durante a formação teórica do docente, na realidade do IFRN-Campus Macau tratam-se dos conhecimentos da biologia que devem ser trabalhados com os alunos permitindo o desenvolvimento humano e cidadão; já os saberes pedagógicos e saberes da experiência são desenvolvidos na prática docente, como por exemplo, no PIBID, no estágio curricular docente e na prática profissional docente, eles são construídos no contexto escolar, nas relações interpessoais, nas práticas docentes individuais e coletivas.

Na fala de Caroá (2015) observa-se a relevância do programa na aproximação entre teoria/prática na medida em que esta afirma que "vamos levar essas experiências para resto de nossas vidas profissionais, a gente aprende muito com o PIBID, com as práticas em sala de aula, a gente passa a enxergar como é importante sempre está unindo a teoria com a prática" (CAROÁ, ENTREVISTA, 2015).

Percebe-se que dentro dos muros da instituição são expostos conhecimentos, métodos e soluções que teoricamente parecem dar conta da realidade escolar, mas quando postos em prática esbarram com as limitações advindas da falta de experiência, como a dificuldade do docente lidar com a subjetividade dos alunos que por vezes torna-se uma barreira a ser quebrada para viabilizar o processo de ensino-aprendizagem.

Desta forma, na trajetória da constituição do ser docente a teoria deve caminhar próxima da prática desde o início dos cursos de formação, para que os licenciandos possam adquirir experiências concretas para construção de sua identidade profissional.

No PIBID os bolsistas têm a oportunidade de conhecer e refletir sobre as diferentes abordagens metodológicas, além do que, o programa requer dos licenciandos uma postura crítica, ética e reflexiva, para que estes possam enfrentar as situações adversas e os desafios crescentes que marcam a prática educativa escolar nos dias atuais.

Quando se projeta a construção de uma postura crítica frente à prática pedagógica como sendo fator fundamental da formação docente, depara-se logo com a fala de Freire (1996, p.39), quando este afirma que "é pensando criticamente a prática de hoje ou de ontem que se pode melhorar a próxima prática".

Nesse sentido, pensar a prática cotidiana criticamente deve promover mudanças que rompam com o hábito e com a rotina do professor, em um processo de ressignificação do fazer docente, sendo esta uma necessidade que se transforma em um desafio constante a ser enfrentado nos processos formativos (Farias, 2009).

Ao analisar as falas dos licenciandos bolsistas é notória a relevância que estes empregam ao PIBID no que refere-se à formação inicial, a medida em que este permite a aproximação da relação da teoria/prática, o contato com a realidade escolar, o exercício da prática docente, entre outros aspectos. 
Em relação à categoria de formação continuada procurou-se compreender a partir dos questionamentos levantados na entrevista a percepção dos licenciandos sobre o papel do programa no processo formativo dos professores supervisores.

No PIBID o professor supervisor tem papel de inserir, acompanhar e orientar os licenciandos na realidade escolar, no que diz respeito a orientação do planejamento pedagógico dos conteúdos a serem trabalhados, no acompanhamento das atividades diferenciadas realizadas pelos licenciados, ele faz uso de suas experiências na educação de modo a oportunizar aos futuros docentes a superação de problemas que possam surgir no percurso de sua formação no contexto da escola.

No momento em que se considera os professores supervisores sujeitos em constante formação, analisou-se os relatos dos licenciandos e verificou-se que para estes as ações formativas advindas do PIBID estão relacionadas com a interação existente entre eles e os professores supervisores, como pode-se perceber nas seguintes falas:

O programa permite a troca de experiências, entre os professores e os licenciandos contribuindo para a formação de ambos (UMBUZEIRO, ENTREVISTA, 2015).

O programa contribui na formação da professora supervisora a partir do momento em que ela está vivenciando com outras pessoas (licenciandos) que vêm de uma realidade totalmente diferente tentando trazer novas metodologias, novas formas de ensino. Eu acho que é uma grande contribuição para ela poder aprender junto com a gente (MACAMBIRA, ENTREVISTA, 2015).

Percebe-se que nas falas dos bolsistas a relação entre licenciandos e professores supervisores não ocorre de maneira unilateral, pois as interações estabelecidas a partir do programa permitem um compartilhamento de ideias e experiências significativas para o processo formativo de ambos os lados envolvidos.

De forma que, o processo formativo é desenvolvido a partir de uma dinâmica de relações sociais, e na realidade do PIBID em que teoricamente o objeto de formação é o licenciando, devese perceber que o professor supervisor não está alheio a este processo, na visão de Freire (1996, p.23) "Quem forma se forma e re-forma ao formar e quem é formado forma-se e forma ao ser formado".

Ao considerar essa possibilidade como sendo válida, e ao observar os relatos dos licenciandos, nota-se que a contribuição do PIBID para formação dos professores supervisores está relacionada à renovação e mudança nas práticas destes sujeitos, mediante as metodologias diferenciadas e novas maneiras de se trabalhar os conteúdos advindos do trabalho coletivo destes com os próprios licenciandos. Verifica-se esta concepção nas seguintes falas:

Pelo professor estar já algum tempo na área de educação ele aderiu a determinada forma de ensinar, com a gente ele vai vendo que existem outras formas que podem melhorar a aprendizagem daquele aluno (QUIPÁ, ENTREVISTA, 2015). 
Por ele ter terminado sua graduação já há algum tempo e como sabemos que sempre vem surgindo coisas novas, eu acho que ele aprende muito com os licenciandos, até questões de novas metodologias, novas formas de ensinar (JUAZEIRO, ENTREVISTA, 2015).

Na formação dos professores [o PIBID] contribui a partir do momento que eles têm uma perspectiva de ensino diferenciado que levamos, pois talvez eles não tenham tido essa formação (BARAÚNA, ENTREVISTA, 2015).

Indo de acordo com estas afirmativas, Oliveira (2012, p. 472) relata que a "viabilização de encontros sistemáticos entre licenciandos em formação inicial e professores supervisores de escolas públicas da educação básica com o objetivo de discutir e promover práticas pedagógicas inovadoras" é um fato inédito realizado pelo PIBID na busca de processos de aprendizagem significativos para os alunos da educação básica.

E nesse sentido, a autora ainda revela que além da formação inicial de professores dois outros processos são relevantes para a melhoria da qualidade da educação básica, que são "a busca e efetivação de metodologias de ensino diferenciadas e a formação continuada de professores" (Oliveira, 2012, p. 472). Levando em conta os resultados analisados nesse construto percebe-se que tais processos estão intimamente relacionados, pois a efetivação de metodologias de ensino diferenciadas está permeada pela inclusão destas na prática dos professores, o que advêm da necessidade de novas experiências formativas desses docentes, assim, o PIBID surge, mesmo que de maneira sutil, como uma ferramenta importante para alcançar estes objetivos.

Quando os docentes estão abertos a compartilhar suas experiências colaborando com a formação inicial dos licenciandos, e, além disso, internalizam novas atitudes e situações permitindo uma reflexão e mudança de sua prática, percebe-se a real possibilidade de uma formação continuada desses professores.

Deste modo, os licenciandos acreditam que a contribuição formativa proporcionada pelo PIBID para os professores supervisores, parte do interesse destes em promover mudanças na sua prática. Outros relatos de bolsistas que atuam na mesma escola, partilham da percepção quanto à mudança real na prática da professora supervisora:

Não sei nas outras turmas, mas eu vejo muito a mudança na atitude dela enquanto professora, eu acho que ela quer contribuir na nossa formação também, então nossa presença lá é um estímulo, ela se sente motivada com a nossa motivação (XIQUEXIQUE, ENTREVISTA, 2015).

Percebemos mudanças, eu atribuo ao convívio com a gente, que planejamos aulas diferentes, agora até ela sugere algumas práticas, ela tem algumas práticas em mente que não planejava antes, acredito pela dificuldade com os alunos, agora com a gente, ela tem mais liberdade de promover aulas práticas (ANGICO, ENTREVISTA, 2015).

Ao realizar uma análise das perspectivas dos licenciandos sobre a interlocução entre formação inicial e continuada a partir do PIBID, percebe-se que estes visualizam o espaço escolar como ambiente colaborativo, em que o professor supervisor contribui para a formação inicial 
deles, ao mesmo ponto em que ao orientá-los estes docentes adquirem novas experiências que também serão significativas para seu processo formativo, permitindo uma formação continuada.

Sendo assim, o PIBID apresenta-se como mediador entre a formação de iniciantes a docência e professores atuantes, na medida em que permite um compartilhamento de conhecimentos na seguinte ótica: os licenciandos contribuem para a formação continuada dos professores supervisores, quando estes levam metodologias diferenciadas que podem ser assimiladas pelos docentes na sua prática pedagógica; e os professores supervisores contribuem para formação inicial dos licenciandos, quando estes atuam orientando os iniciantes a docência, e partilhando os conhecimentos advindos de suas experiências profissionais. Verifica-se esta relação nas seguintes falas:

O licenciando aprende com o professor supervisor por ele já ter uma experiência em sala, que eu acho que só com o tempo se obtém isso, mas ele também aprende com o bolsista pelo sentido das coisas novas que esse aluno traz. Um está ajudando sempre o outro, o convívio entre os dois contribui um para o outro (JUAZEIRO, ENTREVISTA, 2015).

Existe uma troca bem dinâmica entre os graduandos e o professor, o professor traz uma bagagem muito grande do convívio em sala de aula, de você lidar com os conflitos entre os alunos, entre os próprios colegas de trabalho, e a gente traz uma bagagem de formação diferenciada (MANDACARU, ENTREVISTA, 2015).

Sim, por que não somente a gente aprende com ela, como ela também aprende com a gente, um compartilhando com o outro, metodologias, formas de ensino e práticas. É uma construção que vai sendo realizada mutuamente (MACAMBIRA, ENTREVISTA, 2015).

Nessa direção, é pertinente considerar que a integração entre instituição de ensino superior e escolas de educação básica promove a colaboração entre os sujeitos e suas instituições, bem como, atende as necessidades da realidade escolar e as da formação inicial e continuada, o que, no caso deste estudo, se repercute a partir da interlocução entre as práticas dos professores supervisores e os licenciandos.

É válido ressaltar que este processo formativo só é possível com o engajamento tanto de professores supervisores, quanto dos licenciandos, pois estes devem estar abertos ao diálogo, e a reflexão das práticas desenvolvidas no cotidiano, visando à construção de propostas diversificadas e mais qualificadas a fim de atingir a realidade escolar a qual estão inseridos. Sendo assim, o comprometimento com as atividades envolvendo o PIBID é a chave fundamental para promover contribuições significativas para formação docente.

Passando para a percepção dos professores supervisores sobre as contribuições do PIBID para a formação inicial e continuada, nota-se uma aproximação da visão dos licenciandos no que refere-se à relevância do PIBID para formação inicial.

Na perceptiva do professor Azulão (2015) os iniciantes à docência "vêm com a parte teórica do IFRN e aplicam esses conteúdos com os alunos de forma prática, contribuindo para formação desses bolsistas, que já estão inseridos no ambiente escolar, no local onde eles vão trabalhar futuramente". 
Na fala do professor percebe-se que este compreende o papel do programa em aproximar a relação entre teoria e prática, a partir da inserção dos licenciandos na realidade escolar. Ponto de vista que também foi observado nas falas dos bolsistas graduandos.

A compreensão acerca da importância do programa para formação dos iniciantes a docência se faz relevante, pois como professor supervisor este vai atuar articulando essa relação entre teoria e prática, a partir das intervenções a serem realizadas pelos licenciandos no espaço escolar (Batista et al., 2013).

Já a professora Asa-branca (2015) enfatiza a relevância do programa em permitir o contato dos licenciandos com a realidade escolar, devendo este ser um momento estendido para todos os graduandos, nas palavras da professora:

Todos deveriam antes de entrarem em sala de aula terem esse contato de conhecer e realmente sentir-se parte da escola identificando a realidade, porque quando você vivencia e entra na escola conhecendo a realidade, começa a buscar realmente alternativas, em vez de se chocar, ou também achar que vai resolver tudo (ASA-BRANCA, ENTREVISTA, 2015).

Sabe-se que na grade curricular da maioria dos cursos de licenciatura a inserção do licenciando na realidade escolar ocorre através da etapa de estágio supervisionado, mas como já relatado pelos graduandos, o PIBID vem para somar experiências que serão importantes nessa etapa, ou ainda, para expandir e aprimorar as habilidades pedagógicas a partir do contato com o espaço escolar, e construção de um trabalho coletivo junto aos professores supervisores.

Nesse sentido de acordo com Batista et al. $(2013$, p. 2) o professor supervisor na realidade do PIBID assume papel importante ao buscar "elevar o desempenho acadêmico dos licenciandos, uma vez que, enquanto profissionais mais experientes, contribuem para uma formação inicial de qualidade e em consonância com a realidade, com rebatimentos na escola básica".

Posto isto, é essencial que os professores supervisores estejam comprometidos verdadeiramente com o PIBID, pois além de contribuírem para o processo formativo dos licenciandos, também podem valer-se dessas novas experiências para refletirem sobre suas práticas pedagógicas.

No que refere-se à formação continuada, a visão dos professores em relação a contribuição do PIBID está associada ao contato dos docentes com práticas diferenciadas advindas da relação destes, com os licenciandos que atuam no programa.

No seu relato, sobre a experiência como professor supervisor, do subprojeto biologia, o professor Azulão (2015) afirma que:

\footnotetext{
Vi que a forma lúdica, levar os alunos para a prática no laboratório, mostrar o lúdico, eu vi que eles absorvem mais facilmente, eu na realidade, era um professor muito tradicional, é o pincel e o quadro, e hoje estou vendo essa mudança na forma de planejar as aulas, justamente pelo incentivo dos bolsistas, essas práticas ajudam muito nessa parte de compreensão dos conteúdos e eu vejo que isso é uma realidade (AZULÃO, ENTREVISTA, 2015).
} 
Baseado no comentário do educador nota-se que ao ingressar no programa este constatou os resultados positivos provenientes das mudanças metodológicas, tendo com o PIBID a oportunidade de vivenciar novas experiências, novas formas de ver e pensar o fazer docente.

Realizando um paralelo com os discursos dos licenciandos frente ao mesmo tema, percebe-se uma concordância entre as duas perspectivas, pois licenciandos e professor supervisor acreditam que ao atuarem no PIBID, este acaba aprendendo metodologias diferenciadas com os bolsistas, podendo inseri-las em sua prática pedagógica.

Ao analisar as oportunidades de transformação da prática pedagógica, é perceptível o papel significativo do PIBID frente à formação continuada dos professores supervisores, mesmo que ao adentrarem no programa os docentes não tinham em vista esta possibilidade.

Normalmente, nas escolas de educação básica são fornecidas possibilidades de formação continuada a partir da oferta de cursos de atualização de conteúdos que de acordo com Pimenta (2008) pouco contribuem para alterar a prática docente por não levarem em consideração a prática pedagógica na realidade escolar e em seus contextos.

Para a professora Asa-branca (2015) a relação com os licenciandos surge como estímulo à sua prática pedagógica, ao relatar que:

Os bolsistas chegam com propostas que a gente acaba absorvendo, vendo o que dá pra gente aplicar em sala de aula, então abre muito o olhar, a visão de novas atividades, e muitas eu acabo absorvendo, adequando a minha realidade, por que infelizmente a gente não tem a estrutura que poderia ter para fazer uma boa aula, eu digo até a eles que tem que trabalhar na perspectiva em que você se vê sozinho, pois a realidade da escola pública é que o professor está sozinho (ASA-BRANCA, ENTREVISTA, 2015).

Em seu depoimento a professora também enfatiza a relevância do contato com metodologias diferenciadas a partir do trabalho coletivo com os licenciandos, mas esta realiza uma reflexão acerca da inserção dessas metodologias na sua prática docente moldando-as a sua realidade enquanto professora de escola pública.

É importante que os docentes tenham a consciência de que a formação é um processo contínuo, já que estes estão propícios a novas situações de aprendizado, como pode-se verificar nas falas dos entrevistados, dando a possibilidade deles refletirem sobre suas práticas.

Ao serem indagados sobre a interlocução entre formação inicial e continuada a partir do PIBID, os professores supervisores teceram os seguintes comentários:

Existe sim, a gente todo dia aprende algo diferente, seja como montar uma aula, um slide, a forma de passar um conteúdo e isso eles trazem, com certeza os professores aprendem muito com eles, e a gente deve passar alguma coisa que eles fixam a partir dessa relação (AZULÃO, ENTREVISTA, 2015).

Sem dúvida, eles entram com o que estão descobrindo na faculdade trazendo estas novidades, e observam minha relação com os alunos, o convívio e a forma de falar com os alunos, então existe uma troca, em função da minha experiência percebem meu olhar, então eles tem a oportunidade de conhecer um modelo, uma forma de trabalhar e tirar aquilo que eles acharem interessante e se moldarem, o que eu tiro para minha formação é o que eles trazem de novo, e isso eu vou modelando dentro das minhas 
aulas, e em contra partida, eles se inspiram para se modelar em cima daquilo que eles acham interessante do meu perfil (ASA-BRANCA, ENTREVISTA, 2015).

No seu comentário é possível perceber que o professor Azulão (2015) foi sutil ao salientar as contribuições formativas promovidas pela relação entre ele e os licenciandos a partir do programa, já a professora Asa-branca (2015) em sua fala traça proposições importantes no que se refere à construção de uma identidade docente a partir de uma visão reflexiva da prática pedagógica, oportunizada pelas trocas de experiências entre ela e os graduandos.

Contudo, ao analisar as falas dos entrevistados (licenciandos e professores supervisores) percebe-se que estes compartilham de um mesmo pensamento, que o PIBID atua no processo de interlocução entre formação inicial e continuada, pois licenciandos participantes do PIBID adquirem novas experiências a partir da inserção na realidade escolar e do trabalho coletivo realizado com os professores supervisores, e estes, por sua vez, têm contato com metodologias diferenciadas e novas formas de ver o ensino, que podem permitir reflexões e mudanças na prática docente.

Assim é importante que na relação entre professores supervisores e licenciandos, ambos estejam abertos a construção de um diálogo, já que o diálogo e a mediação surgem "no contexto da formação de futuros professores e da formação continuada como competências importantes a serem adquiridas e estimuladas pelos integrantes do programa no desenvolvimento de suas ações" (Matsuaka \& Signorelli, 2013, p. 151).

Tendo isto em vista, ao assumir tais competências os professores supervisores possibilitam um ambiente propício para construção de ideias, e compartilhamento de experiências que serão significativas para a formação dos sujeitos comprometidos.

De acordo com Miranda (2007, p. 21) "exercitar o diálogo e a coletividade pode ser um caminho para superar a cultura do trabalho individual tão comum nas escolas. O professor normalmente atua sozinho, dificilmente recebe ajuda ou orientações que possam favorecer sua prática".

Baseado no que a professora Asa-branca (2015) traz como pontos marcantes de sua participação no PIBID, é relevante salientar o incentivo declarado à renovação de metodologias e de aceitação de diferentes possibilidades no que diz respeito à construção do conhecimento, o que a professora atribui a relação construída entre ela e os licenciandos.

$\mathrm{Na}$ fala do professor Azulão (2015) verificou-se que a relação entre ele, enquanto professor supervisor, e os licenciandos bolsistas do PIBID estaria voltada apenas à assimilação de novos métodos a serem utilizados por ele, algo que poderia ser obtido em um curso de capacitação, ou aprimoramento da prática docente, mas que poderia não permitir as trocas de saberes e experiências entre acadêmicos e professores, nem a integração entre universidade e escola oportunizados pelo PIBID.

\section{CONSIDERAÇÕES FINAIS}

Diante das informações confirmadas nessa pesquisa o PIBID torna-se peça fundamental na formação inicial de docentes, pois permite que os licenciandos sejam inseridos na realidade 
escolar antes mesmo do estágio supervisionado, onde eles podem colocar em prática os conhecimentos teóricos adquiridos no decorrer do curso, colaborando para uma mudança na prática docente, a partir da adição de metodologias diferenciadas no ensino de biologia. E nesse sentido, os professores supervisores têm papel relevante por serem o elo entre licenciandos e escola de educação básica, além de partilharem os conhecimentos advindos de suas experiências profissionais.

Já no que se refere à formação continuada percebeu-se que o PIBID permite uma renovação da prática docente advinda do trabalho coletivo existente entre licenciandos e professores supervisores, já que estes saem da instituição de ensino superior pautados de novos conhecimentos e colocam em prática na realidade da educação básica estimulando mudanças na prática dos próprios professores supervisores.

Ao analisar as perspectivas dos entrevistados sobre a interlocução entre formação inicial e continuada a partir do PIBID notou-se que estes visualizam o espaço escolar como ambiente colaborativo, em que os professores supervisores contribuem para a formação inicial dos licenciandos, ao mesmo ponto em que ao orientarem os iniciantes a docência estes professores adquirem novas experiências que também são significativas para seu processo formativo, permitindo uma formação continuada.

Tendo isto em mente, considera-se que a recepção e a atuação do programa têm sido positivas na comunidade escolar. Assim, afirma-se que todos ganham com o PIBID: A escola, com a melhoria da qualidade do ensino, propondo-se a mudanças em seu cotidiano, ou seja, com a dinâmica do contexto real do trabalho, de modo a colaborar com a profissionalização do ensino. Os bolsistas de iniciação à docência com a formação inicial, e mesmo os professores não percebendo que ao mesmo tempo em que "eles formam, também se formam", o programa contribui para o processo formativo de todos os envolvidos.

Diante de tudo que foi exposto, é válido discorrer que a contribuição do PIBID torna-se cada vez mais evidente na formação acadêmica, social e humana, ao inserir uma nova dinâmica no espaço escolar, permitindo a construção de uma relação entre futuros professores e docentes atuantes que na realização de um trabalho coletivo adquirem experiências significativas para o processo formativo.

Em vista da amplitude do PIBID, enaltece-se a necessidade de mais pesquisas englobando este tema, pois as potencialidades do programa são inúmeras, e espera-se que as descobertas deste construto impulsionem novas buscas nesse sentido, à medida que a complexidade do programa frente à formação e prática docente exige novas perspectivas que venham a contribuir na construção do conhecimento frente a esta temática.

\section{REFERÊNCIAS}

BATISTA, N. N. F. et al. (2013). PIBID/PEDAGOGIA/UFRN: contribuições para a formação docente. $\begin{array}{lllll}\text { Recuperado em } 17 & \text { Maio, } & \text { de }\end{array}$ www.sistemas.ufrn.br/shared/verArquivo?idArquivo=1481767\&key.

BRASIL, Portaria no 096 (2013). Regulamento do programa institucional de bolsa de iniciação à docência.

CUNHA, M. J. de (2014). A importância do PIBID para a formação e a prática docente: um estudo 
de caso na Escola Estadual Professora Clara Tetéo/Macau/RN. Macau/RN, $86 \mathrm{f}$.

FARIAS, I. M. S. de et al. (2009). Didática e Docência: aprendendo a profissão. Brasília: Líber Livro. Pp. 5-76.

FREIRE, P. (1996). Pedagogia da autonomia: saberes necessários à prática educativa. São Paulo: Paz e Terra.

MARCELO, C. (1998). Pesquisa sobre a formação de professores: o conhecimento sobre aprender a ensinar. Recuperado em 29 Março, 2015, de http://anped.org.br/rbe/rbedigital/RBDE09/RBDE09_06_CARLOS_MARCELO.pdf.

MATSUOKA, S. \& SIGNORELLI, G. (2013). Integração universidade e escola pelo PIBID: uma análise das ações formativas de supervisores aos licenciandos. Recuperado em 16 Junho, 2015, de http://iseveracruz.edu.br/revistas/index.php/revistaveras/article/view/132/113.

MIRANDA, M. I. (2007). A extensão universitária e a formação continuada de professores,. $\begin{array}{lllll}\text { Recuperado em } & 16 & \text { Junho, 2015, de }\end{array}$ http://www.unesp.br/prograd/ixcepfe/Arquivos\%202007/8eixo_relatos.pdf.

OLIVEIRA, M. G. (2012). O PIBID-FAE/UFMG e os processos de significação da prática docente RBPG, Brasília, supl. 2, v. 8, pp. 469 - 485, Recuperado em 29 Março, 2015, de http://ojs.rbpg.capes.gov.br/index.php/rbpg/article/view/248/237.

PAREDES, G. G. O. \& GUIMARÃES, O. M. (2012). Compreensões e Significados sobre o PIBID para a Melhoria da Formação de Professores de Biologia, Física e Química. Compreensões e Significados sobre o PIBID. Vol. 34, N 4. pp. 266-277. Recuperado em 02 Junho, 2015, de http://www.ppgecm.ufpr.br/Disserta\%C3\%A7\%C3\%B5es/009_GiulianaGionnaOliviParedes.p df.

PIMENTA, S. G. (2008). Saberes pedagógicos e atividade docente.-6ạ ed.- São Paulo: Cortez,.

WEBER, K. C. et al. (2012). Vivenciando a prática docente em Química por meio do PIBID: introdução de atividades experimentais em escolas Públicas. supl. 2, v. 8. Brasília,.p. 539 559. Recuperado em 02 Junho, 2015, de http://ojs.rbpg.capes.gov.br/index.php/rbpg/article/view/254/243. 